\title{
Birthweight And Postnatal Growth As Predictors of Elevated Blood Pressure In Adolescents of Low Socioeconomic Condition: A Cohort Study In Northeast Brazil
}

Marcelo S Oliveira ( $\sim$ marcelocaleb@gmail.com )

Universidade Federal de Pernambuco https://orcid.org/0000-0002-3284-0034

Fabiana C L S P Gonçalves

Universidade Federal de Pernambuco

Pedro I. C. Lira

Universidade Federal de Pernambuco

Sidrack L Vila Nova Filho

Universidade Federal de Pernambuco

Sophie H Eickmann

Universidade Federal de Pernambuco

Marilia C Lima

Universidade Federal de Pernambuco

\section{Research}

Keywords: catch up growth, low birthweight, blood pressure, hypertension

Posted Date: July 1st, 2021

DOl: https://doi.org/10.21203/rs.3.rs-592145/v1

License: (c) (i) This work is licensed under a Creative Commons Attribution 4.0 International License.

Read Full License 
1 Birthweight and postnatal growth as predictors of elevated blood pressure in

2 adolescents of low socioeconomic condition: a cohort study in Northeast Brazil

3 Short title: Birthweight, growth and elevated blood pressure

4 Marcelo S. OLIVEIRA ${ }^{\mathrm{a}}$, Fabiana C. L. S. P. GONÇALVES ${ }^{\mathrm{b}}$, Pedro I. C. LIRA ${ }^{\mathrm{b}}$, Sidrack

5 L. VILA NOVA FILHO ${ }^{c}$, Sophie H. EICKMANN ${ }^{c}$, Marilia C. LIMAc

6 a Post-graduation Program in Physical Education, Federal University of Pernambuco

$7 \quad$ b Nutrition Department, Federal University of Pernambuco.

$8{ }^{c}$ Post-graduation Program in Child and Adolescent Health, Federal University of

9 Pernambuco.

10 Corresponding author: Marcelo S. Oliveira

11 Address: Rua Comendador Alvares de Carvalho, 114 apt 101 - Iputinga - Recife,

12 Pernambuco, Brazil. Telephone: 55 (81) 9.9835-0366

13 E-mail: marcelocaleb@gmail.com

14 Number of tables: 4 


\section{Abstract}

Objective: To evaluate low birthweight and rapid postnatal weight gain as predictors of elevated blood pressure in adolescence in a population of low socioeconomic status.

Methods: A cohort study was carried out with 208 adolescents, 78 born with low weight and 130 born with appropriate weight. The infants were followed up during the first six postnatal months and reassessed at 8 and 18 years of age. The main exposure variables were birth weight and weight gain in the first six postnatal months. Rapid weight gain was defined when above $0.67 \mathrm{z}$ score. The investigated co-variables were: sex, maternal height and family income at birth, breastfeeding duration from birth to six months, nutritional status at eight years old, socioeconomic conditions, nutritional status, fat mass index and physical activity level at 18 years. The outcome variable was the occurrence of elevated blood pressure at 18 years old.

Results: The proportion of adolescents with elevated blood pressure was $37.5 \%$. The multivariable logistic regression analysis showed the variables independently associated with a higher chance of elevated blood pressure in adolescence were rapid postnatal weight gain $(\mathrm{OR}=2.74 ; 95 \%$ CI 1.22-6.14; $\mathrm{p}=0.014)$, male sex $(\mathrm{OR}=4.15 ; 95 \%$ CI 1.66 10.38; $\mathrm{p}=0.002)$ and being physically active $(\mathrm{OR}=2.70 ; 95 \%$ CI 1.08-6.74; $\mathrm{p}=0.034)$.

Conclusions: The occurrence of rapid weight gain in the first six postnatal months was a predictor for elevated blood pressure in adolescence. This result highlights the influence of factors related to development in early childhood on health problems in the future.

Keywords: catch up growth, low birthweight, blood pressure, hypertension. 
50

\section{INTRODUCTION}

50 pressure exerted by the blood on the walls of arteries and affects approximately 1.13 billion people throughout the world [1]. It is the main chronic noncommunicable disease [2] and the greatest risk factor for heart and cerebrovascular diseases [3].

The symptoms of hypertension rarely appear in the early stages and emerge throughout adulthood, resulting from diverse factors, such as the ageing process, a poorquality diet, excessive alcohol intake, inadequate physical activity, excess weight, and exposure to persistent stress [4]. However, studies have reported an increase in the number of cases found in children [5] and adolescents [6], underscoring the importance of controlling blood pressure (BP) in this phase of life, as the occurrence of high BP in childhood/adolescence is related to hypertension in adulthood [7].

Besides the conditions listed above, others are beyond the control of the individual and may favor the development of an increase in BP, such as low birth weight, preterm birth, and compensatory growth in the first months of life $[8,9]$. Low birth weight is a proxy of fetal growth restriction [10] and is associated with hypertension as well as other comorbidities in adulthood, such as diabetes and coronary artery disease [11]. Children with low birth weight have greater weight gains in the first 24 months of postnatal life [12]. This mechanism seems to have a beneficial effect on the newborn during these first two years [13], but is related to metabolic disorders in adulthood, especially when occurring in the first six months of life [14].

As rapid postnatal weight gain seems to favor the development of chronic diseases and obesity $[15,16]$, it is important to follow up such individuals to ensure the control of the development of chronic noncommunicable diseases and identify this association in 
the early phases of the life cycle. Therefore, the aim of the present study was to evaluate low birth weight and rapid postnatal weight gain as predictors of elevated blood pressure among adolescents in a population with a low socioeconomic status.

\section{METHODS}

\section{Setting and population}

A cohort study was conducted with 208 adolescents recruited at birth, followed up for the first six months of life, and reevaluated at the ages of eight and 18 years. This study was conducted at six maternities in urban areas of five cities in the southern portion of the coastal/forest zone in the state of Pernambuco in northeastern Brazil [17].

\section{Birth cohort and follow-up data}

The study began in 1993 and 1994 with the recruitment of 549 full-term children with a gestational age greater than 37 weeks: 206 with low birth weight (LBW - 1800 to $2499 \mathrm{~g}$ ) and 343 with appropriate birth weight (ABW - 3000 to $3500 \mathrm{~g}$ ). The inclusion criteria were belonging to families who earned up to four times the Brazilian monthly minimum wage as well as the absence of infection, congenital anomalies, and genetic syndromes [18].

The mothers were interviewed using a form with pre-coded closed-ended questions addressing socioeconomic status, mother's exposure to smoke during pregnancy, and characteristics of the newborn. Anthropometric data and information on the duration of breastfeeding were also collected. The children had a median of 40 days of total breastfeeding [19]. 
Between May 2001 and August 2002, when the children were eight years of age, only 213 of the 549 children who composed the initial sample were encountered (86 with LBW and 127 with ABW). These children were reevaluated in terms of socioeconomic status and anthropometric characteristics (weight, height, and waist circumference). No statistically significant difference in socioeconomic status was found between the children who remained and those who dropped out of the study [20].

Between April and September 2012, more than 18 years from the onset of the cohort, 217 adolescents were found and were reevaluated with regards to socioeconomic status, family income per capita, anthropometric characteristics (weight, height, and waist circumference), blood pressure, percentage of body fat, and level of physical activity. Losses to follow-up accounted for $60.47 \%$ of the initial sample, as 217 adolescents were found at 18 years of age. Most losses occurred due to difficulty locating individuals and changes of address to another state. Despite the losses, no statistically significant differences in socioeconomic characteristics were found between those who remained in the study and those who dropped out (Appendix 1).

The present paper involves data from 208 adolescents (71 with LBW and 137 with $\mathrm{ABW}$ ) whose $\mathrm{BP}$ was measured. The $\mathrm{BP}$ of nine adolescents was not analyzed because the cuff of the equipment was inadequate for the arm circumference of these individuals due to obesity. The adolescents in the sample were those with data from six months, eight years, and 18 years of age.

\section{Variables of interest}

The independent variables were birth weight and postnatal weight gain. The following were the covariables in each evaluation phase: at birth - child's sex, height, and birthweight, mother's exposure to smoke during pregnancy, family income 
123 (categorized as $<$ or $\geq$ the Brazilian monthly minimum wage, which corresponded to 124 US\$70 at the time), and total duration of breastfeeding using the median of 40 days as the cutoff point; at eight years of age: body mass index (BMI), waist circumference and gain in BMI between six months and eight years; at 18 years of age: family income per capita, gain in BMI between eight and 18 years, height, BMI, fat mass index, and physical activity level. The outcome variable was elevated blood pressure at 18 years of age.

\section{Anthropometric evaluation}

At birth, anthropometric characteristics (weight and length) and gestational age determined using the method proposed by Capurro et al. [21] were recorded within the first 24 hours of life. The anthropometric characteristics were determined again in the home setting at a frequency of twice per week until the children had completed 26 weeks of age. Growth rate was classified as rapid when the difference in the $\mathrm{Z}$ score for the weight for age index between six months of age and birth was more than 0.67 standard deviations [22], considering the curves of the [23].

At eight years of age, BMI according to age and sex was calculated with the aid of the Anthro Plus software and classified as excess weight (when higher than one standard deviation) or normal weight ( $\leq$ one standard deviation), considering the curves of the [24]. Waist circumference was measured at the midpoint between the edge of the last rib and the iliac crest using a non-elastic metric tape (Lasso; Child Growth Foundation) with the children in underwear, feet in a relaxed posture, arms alongside the body, feet together, and weight distributed evenly between the feet. The measurement was performed in triplicate for all individuals and the mean of the three values was considered for the data analysis. The cutoff point for the classification of high central fat mass was the $80^{\text {th }}$ percentile proposed by Taylor et al. [25]. 
Weight and height of the adolescents were determined for the calculation of the BMI $\left(\mathrm{kg} / \mathrm{m}^{2}\right)$. Weight was determined using a digital scale (Filizola) with a capacity of up to $150 \mathrm{~kg}$ and was recorded with a precision of $0.1 \mathrm{~kg}$. The adolescents wore light clothing and weight was measured with the individual standing on the center of the

152 platform of the scale with body weight distributed evenly between the feet and gazing 153 forward, as recommended by Gibson (2005) [26]. Height was measured using a stadiometer with a sliding scale (Leicester Height Measure - Child Growth Foundation). The adolescents were instructed to remove any jewelry and accessories from the head, stand erect with the head positioned parallel to the horizontal plane, knees extended, feet together, arms alongside the body, palms turned toward the thighs, and ankles, buttocks, and shoulders in contact with the stadiometer. Height was measured twice and the mean of the two measurements was considered for the analysis. If a difference of more than 0.5 $\mathrm{cm}$ was found between the measurements, height was measured a third time and the two closest measurements were used for the determination of the mean. Median height according to sex was considered as the cutoff point to establish categories.

BMI at six months, eight years, and 18 years of age was transformed into z scores based on the distribution curve of the population studied. Differences in BMI in z scores between eight years and six months as well as between 18 years and eight years were considered to determine the growth gain in these periods. The same cutoff point for weight gain between birth and six months of age was adopted.

Waist circumference was measured on the adolescents in the same manner as performed at eight years of age. The waist circumference of three female adolescents who were pregnant for more than 12 weeks was not considered in the study. 
Bioelectrical impedance analysis (BIA) was performed to determine the body

173

174

175 composition of the adolescents using the Maltron tetrapolar BF-906 device. The adolescents were instructed to avoid physical exercise in the 12 hours prior to the exam, not ingest alcohol, tea, coffee, effervescent or energy beverages in the 24 hours prior to the exam, eat up to three hours prior to the exam, and urinate 30 minutes prior to the exam. During the reading, the adolescents were instructed to remain lying on the nonconductive surface with legs and arms separated from the trunk. The adhesive electrodes were attached to the hand, wrist, foot, and ankle on the right side of the body [27].

Pregnant adolescents, those suspected to be pregnant, and those who did not follow the instructions were not submitted to this evaluation, which led to the exclusion of 12 subjects. Data on fat weight obtained through BIA were used to identify the proportion of body fat mass using the fat mass index [fat mass $(\mathrm{kg}) / \mathrm{height}$ squared $\left(\mathrm{m}^{2}\right)$ ] [28]. Adolescents with a fat mass index higher than the median for their sex were considered to have excess body fat.

\section{Physical activity}

The level of physical activity was classified based on the intensity, frequency, and duration of the activity on a weekly basis. For such, the short version of the International Physical Activity Questionnaire (IPAQ) was used [29]. Physical activity level was analyzed as a categorical variable (sedentary or active). Individuals who did not practice any physical activity and those who practiced only light activities were classified as sedentary, whereas those who practiced light activities plus moderate or intense activities and those who practiced moderate or intense activities were classified as active.

\section{Blood pressure}


For the adolescents, BP was measured on the right arm, which was relaxed and supported on a table, with the adolescent in the sitting position with feet supported on the floor. A digital device (Omron, HEM FL 31) with a precision of $1 \mathrm{mmHg}$ and a 22-42 cm cuff were used. The reading was performed twice after five minutes of rest and with a five-minute rest period between readings. When the difference between readings was more than $1 \mathrm{mmHg}$, a third reading was performed 10 minutes after the first reading. The mean of the two closest readings was used for analysis. Values of $>120 \mathrm{mmHg}$ for systolic pressure and/or $>80 \mathrm{mmHg}$ for diastolic pressure were considered for the classification of elevated blood pressure [30].

\section{Statistical analysis}

The processing of the data was performed with the aid of the Statistical Package for the Social Sciences, version 15.0 for Windows (SPSS Inc., Chicago, IL, USA). The Kolmogorov-Smirnov test was used to determine the pattern of normality of the outcome variable (systolic and diastolic pressure) and the null hypothesis was accepted. The Student's t-test was used for the comparison of the means of systolic and diastolic pressure according to the explanatory variables. The outcome variables were categorized and Pearson's chi-square test was used with the level of significance set at $5 \%(\mathrm{p} \leq 0.05)$. The predictor effect of the independent variables on the outcomes was evaluated using multivariate logistic regression analysis with a hierarchical model for the incorporation of variables. For such, a block modeling process was employed. This model was previously established considering a logical relation between the exposure variables and outcome. All variables with a p-value $<0.10$ in the bivariate analysis were selected for the regression analysis to restrict the number of variables incorporated into the analysis as a function of the sample size. As BMI and waist circumference were highly 
correlated, only the latter was incorporated into the regression analysis due to its relation to greater cardiovascular risk and the quantity of visceral adipose tissue [31]. All variables remained in the final model.

\section{Ethical aspects}

This study received approval from the Human Research Ethics Committee of the Center for Health Sciences of the Federal University of Pernambuco (certificate $n^{\circ} 336 / 08$ from December $\left.14^{\text {th }}, 2009\right)$ and was conducted in accordance with the ethical aspects stipulated in the Declaration of Helsinki as well as Resolution $n^{\circ}$. 196/1996 of the Brazilian National Board of Health. The legal guardians signed a statement of informed consent authorizing the participation of the adolescents in the study. When the adolescent was his/her own legal guardian, he/she signed the statement.

\section{RESULTS}

Among the 208 adolescents evaluated, the female sex accounted for 59.6\% and the prevalence of elevated blood pressure was $37.5 \%$. A total of $66.6 \%$ of the adolescents had a family income per capita less than half the Brazilian monthly minimum wage and $20.2 \%$ had excess weight. Regarding the variables at birth and six months of age, $34.1 \%$ had low birth weight, $59.1 \%$ had a family income less than the Brazilian monthly minimum wage and, among the 156 evaluated at six months of age, $39.7 \%$ had rapid postnatal weight gain. Among the 150 adolescents evaluated at eight years of age, $21.3 \%$ had excess weight.

The adolescents with the highest mean systolic pressure were males, those whose mothers were taller, and those who had a family income equal to or higher than the Brazilian monthly minimum wage at birth. A high mean systolic pressure was also found 
247 in adolescents who exhibited rapid weight gain in the first six months of life as well as those who, at eight years of age, had excess weight and a high waist circumference. At 18 years, having height above the median, excess weight, and being physical active were also associated with a higher mean systolic arterial pressure (Table 1).

Higher mean diastolic arterial pressure was found among adolescents whose mothers were taller, those who, at eight years of age, had a high waist circumference, and those who, at 18 years of age, were taller, had excess weight, and had excess body fat (Table 1).

A greater frequency of elevated blood pressure in adolescence was found among males, those who had rapid postnatal weight gain, excess body weight, a high weight circumference, as well as those who were taller in adolescence (Table 2).

The results logistic regression analysis of the factors associated with elevated blood pressure in adolescence are displayed in Table 3. The likelihood of having elevated blood pressure was greater among adolescents who had rapid postnatal weight gain $\mathrm{p}=0.002)$ associated with this outcome in a birth cohort involving a population with a low socioeconomic status. Among the main results, we identified that rapid weight gain in the $(\mathrm{OR}=2.74 ; 95 \%$ CI $1.22-6.14 ; \mathrm{p}=0.014)$, those who reported being physically active $(\mathrm{OR}=2.7 ; 95 \%$ CI 1.08-6.74; $\mathrm{p}=0.034)$, and males $(\mathrm{OR}=4.15 ; 95 \%$ CI 1.66-10.38;

\section{DISCUSSION}

The present study evaluated low birth weight and rapid postnatal weight gain as predictors of elevated blood pressure in adolescence and identified other factors first six months of life was independently associated with a greater chance of elevated 
272 blood pressure in adolescence. Other factors independently associated with this outcome

273

274

275

276

277

278

279

280

281

282

283

284

285

286

287

288

289

290

291

292

293

294

295

296 were the male sex and being physically active.

The longitudinal design with follow-up since birth enabled obtaining information on the growth of the children in a systematic manner from birth to six months as well as in childhood and adolescence. After 18 years of follow-up and reevaluations of the same population, it was possible to investigate whether deviations in normal growth that occurred during the "window of opportunity" for child development may be risk factors for health problems in the future.

Exposure to adverse health problems in the critical phases of development (prenatal and postnatal periods) and associations with adaptations that have consequences for health in adulthood have been discussed for several years in the literature [32]. A poor nutritional status for the fetus can lead to low birth weight, which, in turn, is associated with a greater risk of rapid postnatal weight gain [15]. Rapid weight gain in the first months of life is initially a protective response that favors the maintenance of the child's life and adaptations to the extrauterine environment [13]. However, this compensatory mechanism can lead to changes in hormone concentrations and hormonal sensitivity in difference tissues, the inadequate development of organs, and, consequently, a predisposition to metabolic and cardiovascular complications in adulthood, including hypertension [33].

No association was found between low birth weight and elevated blood pressure in adolescence in the present study. However, a greater likelihood of elevated blood pressure was found among the adolescents who had rapid postnatal weight gain. These results are in agreement with findings described by Bustos et al. [34], who reported no association between low birth weight and higher BP in adolescence. In environments with a low social economic status, the association between low birth weight and higher BP 
297

levels was found when children also exhibited rapid postnatal weight gain [35]. This suggests that rapid weight gain may be an early determinant of the risk for hypertension in subsequent phases of the life cycle.

In an investigation conducted to identify which of these two factors (low birth weight and rapid postnatal weight gain) was more important to the development of high BP, Kelishadi et al. [36] found that only those with rapid postnatal weight gain were at greater risk for hypertension. Subsequent studies confirmed this finding $[37,14,38]$.

Regarding the effect of postnatal weight gain on health in adulthood, Metcalfe and Monaghan [39] presented the notion of "grow now, pay later", by which rapid growth at the onset of life is associated with metabolic and cardiovascular complications in adulthood. However, other studies observed signs of these complications, including an increase in BP, before reaching adulthood. Singhal et al. [40] concluded that rapid weight gain at the onset of life, independently of the type of feeding in this period, promoted an increase in BP at six and eight years of age. The same findings were seen at 10 years of age [38] and in adolescence [39, 41].

The mechanisms involved in the late onset increase in BP after rapid postnatal weight gain have not yet been clarified. According to Singhal [42], rapid postnatal weight gain is associated with obesity, low sensitivity to insulin, low HDL cholesterol, high triglyceride levels, and markers of atherosclerosis at 18 years of age. These factors predispose individuals to hypertension and the risk of cardiovascular disease.

Upon finding that low birth weight and rapid postnatal weight gain up to three years of age were associated with an increase in uric acid and BP, Park et al. [43] suggested that being born with a low weight leads to less development of the renal system, promoting hyperfiltration due to the lower number of nephrons and, consequently, systemic hypertension. This response may be more accentuated in those with rapid 
322 postnatal weight gain. Besides the lower number of nephrons, there is also a lower 323 quantity of glomeruli, which, when associated with the increase in metabolic demand 324 stemming from the accelerated weight gain, leads to the early development of hypertension [44]

Children with a high waist circumference at eight years of age were threefold more likely to have elevated blood pressure in adolescence. The fact that this association had only borderline significance in the multivariate logistic regression $(p=0.078)$ was probably due to the small sample size, as suggested by the wide confidence interval. This association has biological relevance, as a high waist circumference indicates greater deposition of body fat, especially visceral fat, which is an independent predictor of morbidity and mortality due to cardiovascular disease [31]. Therefore, this variable warrants further investigation.

Adolescents who reported being more active had a greater likelihood of elevated blood pressure. This finding is contrary to the well-documented benefits of physical activity regarding the prevention and control of hypertension $[45,46,5,6]$ Reporting a similar result to that of the present investigation, Tsioufis et al. [47] and Teh et al. [48] justified this unexpected finding to a possible overestimation of physical activity performed by the respondents due to the fact that the IPAQ is self-reported. We also consider this possibility. According to Lee et al. [49], there is a possible overestimation in the level of physical activity reported through the IPAQ of around $84 \%$.

A greater likelihood of elevated blood pressure was found in male adolescents. This association has also been found in previous studies [5, 6, 41]. According to Maranon and Reckelhoff [50], this finding may be secondary to sex hormones, as female hormones are associated with protective factors (vasodilation, a reduction in the synthesis of angiotensin II, and a reduction in the response to aldosterone), whereas androgens 
347 contribute to the emergence of hypertension due to the greater activation of the 348 sympathetic nervous system, greater sodium reuptake in the proximal tubule, and an 349 increase in the synthesis of angiotensin). Differences between the sexes also mediate the 350 relations of catecholamines in alpha and beta adrenergic receptors, promoting greater 351 sympathetic activity and, consequently, an increase in BP in men [51]. The present study has limitations that should be considered. Losses to follow-up are a common occurrence in longitudinal studies, especially in developing countries, and impede the evaluation of the same individuals in all steps of the investigation. Moreover, it was not possible to evaluate body fat with other more accurate methods to identify the quantity of body fat and investigate the association with blood pressure. Another limitation was the evaluation of physical activity level using an instrument that may not have been precise enough to measure the intensity of the activities.

In conclusion, the present findings lend strength to the hypothesis that events in

critical phases of development are associated with future adverse health conditions. It is important to investigate factors associated with elevated blood pressure at early ages of the life cycle prior to the development of hypertension. Among such factors, the present study highlights rapid postnatal weight gain, indicating that children with this growth deviation in the first months of life seem to be predisposed to an increase in blood pressure independently of their birth weight and other factors throughout life. Thus, such individuals should be regularly followed up to minimize the accumulation of other risk factors for hypertension.

Abbreviations 
372

BP - blood pressure

373

BIA - bioelectrical impedance analysis

374 BMI - body mass index

375 CI - confidence interval

$376 \quad$ FMI - fat mass index

377 LBW - low birth weight

378 MW - minimum wage

379 OR - odds ratio

380 SD- standard deviation

381 WC - waist circumference

382

383

384

385

386

387

388

389

390

391

392

393

WHO - World Health Organization

Ethical aspects

ACKNOWLEDGEMENTS: The authors deeply appreciate the participation of the mothers, children and adolescents and the dedication of the field workers during the data collection process. This study received funding from the Welcome Trust-UK (grant numbers: 036605/Z/92, 064220Z/01Z) and the Conselho Nacional de Desenvolvimento Científico e Tecnológico (CNPq [National Council of Scientific and Technological Development), Brazil (grant numbers: 476891/2001-9, 472706/2009-8).

This study received approval from the Human Research Ethics Committee of the Center for Health Sciences of the Federal University of Pernambuco (certificate ${ }^{\circ}$ 336/08 
394 from December $14^{\text {th }}, 2009$ ) and was conducted in accordance with the ethical aspects

395

396

397

398

399

400

401

402

403

404

405

406

407

408

409

410

411

412

413

414

415

416

417

418 stipulated in the Declaration of Helsinki as well as Resolution $n^{\circ} .196 / 1996$ of the Brazilian National Board of Health. The legal guardians signed a statement of informed consent authorizing the participation of the adolescents in the study. When the adolescent was his/her own legal guardian, he/she signed the statement.

Consent for publication: We agree with the publication of the study.

Availability of data and materials: Not to be made available.

Competing of interest: There are no conflicts of interest.

Funding: Wellcome Trust-UK (grant numbers: 036605/Z/92, 064220Z/01Z) and the Conselho Nacional de Desenvolvimento Científico e Tecnológico (CNPq [National Council of Scientific and Technological Development], Brazil (grant numbers: $476891 / 2001-9,472706 / 2009-8)$

Authors' contributions: Marcelo Oliveira: conceived, designed the study, analyzed and interpreted the data and drafted the manuscript. Pedro Lira e Fabiana Gonçalves: conceived, designed the study, analyzed and interpreted the data. Marilia Lima: conceived and designed the study, drafted the manuscript and supervised data. Sidrack Filho: analyzed and interpreted the data. Fabiana Gonçalves and Sophie Eickmann: provided advice and a critical revision of the manuscript.

Acknowledgements: The authors deeply appreciate the participation of the mothers, children and adolescents and the dedication of the field workers during the data collection process. This study received funding from the Welcome Trust-UK (grant numbers: 036605/Z/92, 064220Z/01Z) and the Conselho Nacional de Desenvolvimento Científico e Tecnológico (CNPq [National Council of Scientific and Technological Development), Brazil (grant numbers: 476891/2001-9, 472706/2009-8). 
419

420

421

422

423

424

425

426

427

\section{REFERENCES}

[1] World Health Organization. Noncommunicable Diseases Country Profiles 2018. World Health Organization 2018.

[2] Kaptoge S, Pennells L, De Bacquer D, Cooney MT, Kavousi M, Stevens G, et al. World Health Organization cardiovascular disease risk charts: revised models to estimate risk in 21 global regions. Lancet Glob Heal 2019; 7:e1332-45.

[3] Whelton PK, Carey RM, Aronow WS, Casey DE, Collins KJ, Himmelfarb CD, et al. 2017 ACC/AHA/AAPA/ABC/ACPM/AGS/APhA/ ASH/ASPC/NMA/PCNA guideline for the prevention, detection, evaluation, and management of elevated blood pressure in adults a report of the American College of Cardiology/American Heart Association Task Force on Clinical Practice Guidelines. J Am Coll Cardiol 2018; 71:E127-148.

[4] World Health Organization. A global brief on hypertension: silent killer, global public health crisis: World Health Day 2013. World Health Organization 2013.

[5] Dong Y, Song Y, Zou Z, Ma J, Dong B, Prochaskab JJ. Updates to pediatric hypertension guidelines: influence on classification of elevated blood pressure in children and adolescents. J Hypertens 2019; 37:297-306. 
440 [6] Ferguson T, Younger-Coleman NOM, Tulloch-Reid MK, Bennett NR, Rousseau

441 AE, Knight-Madden JM, et al. Factors associated with elevated blood pressure or

442 hypertension in Afro-Caribbean youth: a cross-sectional study. PeerJ 2018; 6:e4385.

444 [7] Tirosh A, Afek A, Rudich A, Percik R, Gordon B, Ayalon N, et al. Progression of 445 normotensive adolescents to hypertensive adults: A study of 26980 teenagers.

446 Hypertension 2010; 56:203-209.

447

448

[8] Visentin S, Grumolato, F, Nardelli GB, Di Camillo B, Grisan E, Cosmi E. Early

449 origins of adult disease: Low birth weight and vascular remodeling. Atherosclerosis

$450 \quad 2014 ; 237: 391-399$.

451

452 [9] Crump C, Howell EA, Stroustrup A, McLaughlin MA, Sundquist J, Sundquist K.

453 Association of Preterm Birth With Risk of Ischemic Heart Disease in Adulthood. JAMA

$454 \quad$ Pediatr 2019; 173:736-743.

455

456 [10] World Health Organization. Global nutrition targets 2025: low birth weight policy 457 brief (WHO/NMH/NHD/14.5). World Health Organization 2014; 1:8.

459 [11] Vaiserman AM. Birth weight predicts aging trajectory: A hypothesis. Mech Ageing 460 Dev 2018; 173:61-70. 
462 [12] Jaquet D, Deghmoun S, Chevenne D, Collin D, Czernichow P, Lévy-Marchal C.

463 Dynamic change in adiposity from fetal to postnatal life is involved in the metabolic 464 syndrome associated with reduced fetal growth. Diabetologia 2005; 48:849-855.

465

466

[13] Victora CG, Barros FC, Horta BL, Martorell R. Short-term benefits of catch-up

467 growth for small-for-gestational-age infants. Int J Epidemiol 2001; 30:1325-1330.

468

469

[14] Oh, JH, Hong, Y. M. Blood pressure trajectories from childhood to adolescence in 470 pediatric hypertension. Korean Circ J 2019; 49:223-237.

471

472

[15] Jain V, Singhal A. Catch up growth in low birth weight infants: Striking a healthy

473 balance. Rev Endocr Metab Disord 2012; 13:141-147.

474

475

[16] Kramer MS, Martin RM, Bogdanovich N, Vilchuk K, Dahhou M, Oken E. Is 476 restricted fetal growth associated with later adiposity? Observational analysis of a 477 randomized trial. Am J Clin Nutr 2014; 100:176-181.

479 [17] Lira PI, Ashworth A, Morris SS. Low birth weight and morbidity from diarrhea 480 and respiratory infection in northeast Brazil. J Pediatr 1966; 128:497-504. 
482 [18] Ashworth A, Morris SS, Lira PIC. Postnatal Growth Patterns of Full-Term Low

483 Birth Weight Infants in Northeast Brazil Are Related to Socioeconomic Status. J Nutr $484 \quad 1997 ; 127: 1950-1956$.

485

486

[19] Gonçalves FCLSP, Amorim RJM, Eickmann SH, Lira PIC, Lima MC. The

influence of low birth weight body proportionality and postnatal weight gain on anthropometric measures of 8-year-old children: a cohort study in Northeast Brazil. Eur J Clin Nutr 2014; 68:876-881.

490

[20] Amorim RJM, Lima MC, Lira PIC, Emond AM. Does low birthweight influence 492 the nutritional status of children at school age? A cohort study in northeast Brazil. Matern Child Nutr 2011; 7:295-306. diagnosis of gestational age in the newborn infant. J Pediatr 1978; 93:120-122. postnatal catch-up growth and obesity in childhood: prospective cohort study. $B M J$ 2000; 320:967-971 
504 [24] The World Health Organization Child Growth Standards 2006/2007. [acessed in

505 09/04/2019]. Available at: http://www.who.int/childgrowth/en

506

507 [25] Taylor RW, Jones IE, Williams SM, Goulding A. Evaluation of waist

508 circumference, waist-to-hip ratio, and the conicity index as screening tools for high

509 trunk fat mass, as measured by dualenergy X-ray absorptiometry, in children aged 3-19

510 y. Am J Clin Nutr 2000; 72:490-495

511

512 [26] Gibson RS. Principals of Nutritional Assessment. Oxford: Oxford University Press;

5132005.

514

515 [27] Vanitallie TB, Yang MU, Heymsfield SB, Funk RC, Boileau RA. Height-

516 normalized indices of the body's fat-free mass and fat mass: potentially useful

517 indicators of nutritional status. Am J Clin Nutr 1990; 52:953-959.

518

519 [28] Lukaski HC, Johnson PE, Bolonchuk WW, Lykken GI. Assessment of fat-free

520 mass using bioelectrical impedance measurements of the human body. Am J Clin Nutr

$521 \quad 1985 ; 41: 810-817$. 
523 [29] Matsudo S, Araújo T, Marsudo V, et al. International Physical Activity

524 Questionnaire (IPAQP): study of validity and reliability in Brazil. Rev Bras Ativ Fis

525 Saúde 2001; 6:5-18

526

527 [31] Flynn JT, Falkner BE. New clinical practice guideline for the management of

528 elevated blood pressure in children and adolescents. Hypertension 2017; 70:683-686.

529

530

[32] Ross R, Neeland IJ, Yamashita S, Shai I, Seidell J, Magni P, et al. Waist

531

circumference as a vital sign in clinical practice: Consensus Statement from the IAS and

532

ICCR Working Group on Visceral Obesity. Nat Rev Endocrinol 2020; 16:177-189.

533

534

535 [33] McMillen IC, Robinson JS. Developmental origins of the metabolic syndrome:

536 Prediction, plasticity, and programming. Physiol Rev 2005; 85:571-633.

537

538

[34] Mandy M, Nyirenda M. Developmental Origins of Health and Disease: The

539

relevance to developing nations. Int Health 2018; 10:66-70.

540

541 [35] Bustos P, Amigo H, Bangdiwala SI, Pizarro T, Rona RJ. Does the association

542 between birth weight and blood pressure increase with age? A longitudinal study in 543 young adults. J Hypertens 2016; 34:1062-7. 
545 [36] Barker DJP, Forsén T, Eriksson JG, Osmond C. Growth and living conditions in

546 childhood and hypertension in adult life: A longitudinal study. J Hypertens. 2002;

$547 \quad 20: 1951-1956$.

548

549 [37] Kelishadi R, Haghdoost AA, Jamshidi F, Aliramezany M, Moosazadeh M. Low

550 birthweight or rapid catch-up growth: Which is more associated with cardiovascular

551 disease and its risk factors in later life? A systematic review and cryptanalysis. Paediatr 552 Int Child Health 2015; 35:110-123.

553

554 [38] Lule SA, Namara B, Akurut H, Muhangi L, Lubyayi L, Nampijja M, et al. Are 555 birthweight and postnatal weight gain in childhood associated with blood pressure in 556 early adolescence? Results from a Ugandan birth cohort. Int J Epidemiol 2019; 48:148557156.

558

559 [39] Perng W, Rifas-Shiman SL, Kramer MS, Haugaard LK, Oken E, Gillman MW, et 560 al. Early Weight Gain, Linear Growth, and Mid-Childhood Blood Pressure.

561 Hypertension 2016; 67:301-308.

562

563 [40] Metcalfe NB, Monaghan P. Compensation for a bad start: Grow now, pay later?

564 Trends Ecol Evol 2001; 16:254-260. 
566 [41] Singhal A, Cole TJ, Fewtrell M, Kennedy K, Stephenson T, Elias-Jones A, et al.

567 Promotion of faster weight gain in infants born small for gestational age: Is there an 568 adverse effect on later blood pressure? Circulation 2007; 115:213-220.

569

570

[42] Raphadu TT, Staden M Van, Dibakwane WM, Monyeki KD. A Non-Invasive

571 Investigation into the Prevalence of Higher than Normal Blood Pressure, Hypertension

572 and the Association between Blood Pressure and Body Weight in Male and Female

573 Adolescents in the Polokwane Local Municipality, Limpopo-South Africa: A Cros.

574 Children 2020; 7:18.

575

576

[43] Singhal A. Long-Term Adverse Effects of Early Growth Acceleration or Catch-Up

577

Growth. Ann Nutr Metab 2017; 70:236-240.

578

579

[44] Park B, Park B, Lee HA, Lee S, Han H, Park E, et al. Association between pre-and

580 postnatal growth and longitudinal trends in serum uric acid levels and blood pressure in

581 children aged 3 to 7 years. BMC Pediatr 2020; 20:23.

582

583 [45] Al Salmi I, M Shaheen FA, Hannawi S. Birth weight, gestational age, and blood

584 pressure: Early life management strategy and population health perspective. Saudi J

Kidney Dis Transpl 2019; 30:299. 
587 [46] Arnett DK, Blumenthal RS, Albert MA, Buroker AB, Goldberger ZD, Hahn EJ, et 588 al. ACC/AHA Guideline on the Primary Prevention of Cardiovascular Disease: A 589 Report of the American College of Cardiology/American Heart Association Task Force 590 on Clinical Practice Guidelines. J Am Coll Cardiol 2019; 74:e177-e232

591

[47] Williams B, Mancia G, Spiering W, Agabiti Rosei E, Azizi M, Burnier M, et al.

2018 ESC/ESH Guidelines for the management of arterial hypertension: The Task

594 Force for the management of arterial hypertension of the European Society of

595 Cardiology and the European Society of Hypertension. J Hypertens 2018, 36:19535962041.

597

598

[48] Tsioufis C, Kyvelou S, Tsiachris D, Tolis P, Hararis G, Koufakis N, et al. Relation 599 between physical activity and blood pressure levels in young Greek adolescents: The 600 Leontio Lyceum Study. Eur J Public Health 2011; 21:63-68.

601

602

[49] Teh CH, Chan YY, Lim KH, Kee CC, Lim KK, Yeo PS, et al. Association of 603 physical activity with blood pressure and blood glucose among Malaysian adults: A 604 population-based study Chronic Disease epidemiology. BMC Public Health 2015;

605 15:1205.

606 
608 physical activity questionnaire short form (IPAQ-SF): A systematic review. Int J Behav

$609 \quad$ Nutr Phys Act 2011; 8:115.

610

611 [51] Maranon R, Reckelhoff JF. Sex and Gender Differences in Control of Blood

612 Pressure. Clin Sci [Internet]. 2013; 125:311-318. Available at:

613 https://www.ncbi.nlm.nih.gov/pmc/articles/PMC3624763/pdf/nihms412728.pdf

614

615 [52] Joyner MJ, Wallin BG, Charkoudian N. Sex differences and blood pressure

616 regulation in humans. Exp Physiol 2016; 101:349-355.

617

618

619

620

621

622

623

624

625

626

627 
TABLE 1. Mean systolic and diastolic blood pressure of adolescents according to variables

\begin{tabular}{|c|c|c|c|c|c|c|c|}
\hline \multirow[t]{2}{*}{ Variables } & \multicolumn{4}{|c|}{$\begin{array}{l}\text { Systolic blood pressure } \\
(\mathrm{mmHg})\end{array}$} & \multicolumn{3}{|c|}{$\begin{array}{l}\text { Diastolic blood pressure } \\
(\mathrm{mmHg})\end{array}$} \\
\hline & $\mathbf{N}(\%)$ & Mean & SD & $\mathbf{p}$ & Mean & SD & $\mathbf{P}$ \\
\hline \multicolumn{8}{|l|}{ At birth } \\
\hline \multicolumn{8}{|l|}{ Sex } \\
\hline Male & $84(40.4)$ & 123.76 & $(12.48)$ & \multirow[t]{2}{*}{$<0.001$} & 72.14 & $(8.44)$ & \multirow[t]{2}{*}{0.549} \\
\hline Female & $124(59.6)$ & 112.86 & (11.18) & & 71.41 & $(8.64)$ & \\
\hline \multicolumn{8}{|l|}{ Birth weight } \\
\hline Low weight & $71(34.1)$ & 117.73 & $(11.05)$ & \multirow[t]{2}{*}{0.692} & 71.81 & $(6.84)$ & \multirow[t]{2}{*}{0.901} \\
\hline Appropriate weight & $137(65.9)$ & 116.99 & (13.73) & & 71.66 & $(9.33)$ & \\
\hline \multicolumn{8}{|l|}{ Maternal height (cm) } \\
\hline$\geq 150$ & $168(80.8)$ & 118.19 & $(12.60)$ & \multirow[t]{2}{*}{0.030} & 72.44 & $(8.68)$ & \multirow[t]{2}{*}{0.012} \\
\hline$<150$ & $40(19.2)$ & 113.34 & $(12.70)$ & & 68.68 & (7.33) & \\
\hline \multicolumn{8}{|l|}{ Family income (MW) } \\
\hline$<1$ & $123(59.1)$ & 115.78 & $(11.67)$ & \multirow[t]{2}{*}{0.050} & 71.09 & $(8.01)$ & \multirow[t]{2}{*}{0.207} \\
\hline$\geq 1$ & 85 (40.9) & 119.33 & $(14.21)$ & & 72.62 & $(8.86)$ & \\
\hline \multicolumn{8}{|c|}{ At six month $(N=156)$} \\
\hline \multicolumn{8}{|c|}{ Postnatal weight gain (SD) } \\
\hline$>0.67$ & $62(39.7)$ & 120.61 & $(12.42)$ & \multirow[t]{2}{*}{0.007} & 73.43 & $(8.57)$ & \multirow[t]{2}{*}{0.095} \\
\hline$\leq 0.67$ & $94(60.2)$ & 114.74 & $(13.81)$ & & 70.94 & $(9.27)$ & \\
\hline \multicolumn{8}{|l|}{ At 8 years $(N=150)$} \\
\hline \multicolumn{8}{|l|}{ BMI } \\
\hline Overweight/obesity & $32(21.3)$ & 124.00 & $(13.52)$ & \multirow[t]{2}{*}{0.003} & 73.75 & $(8.24)$ & \multirow[t]{2}{*}{0.249} \\
\hline Adequated/thinness & $118(78.7)$ & 116.13 & (12.38) & & 71.68 & $(9.13)$ & \\
\hline \multicolumn{8}{|l|}{ Waist circumference } \\
\hline Increased & $17(11.3)$ & 127.88 & $(12.41)$ & \multirow[t]{2}{*}{0.001} & 76.35 & $(8.44)$ & \multirow[t]{2}{*}{0.038} \\
\hline Normal & $133(88.7)$ & 116.51 & (13.28) & & 71.58 & $(8.91)$ & \\
\hline \multicolumn{8}{|c|}{$\begin{array}{l}\text { BMI gain between } 6 \text { month } \\
\text { and } 8 \text { years* (SD) }\end{array}$} \\
\hline$>0.67$ & $19(16.5)$ & 122.47 & $(14.22)$ & \multirow[t]{2}{*}{0.134} & 74.89 & $(7.25)$ & \multirow[t]{2}{*}{0.218} \\
\hline$\leq 0.67$ & $96(83.5)$ & 117.12 & $(14.10)$ & & 71.96 & $(9.79)$ & \\
\hline
\end{tabular}

\section{At 18 years}

Per capita family income

(MW) \#

$<0.5$

$\geq 0.5$

$96(83.5) \quad 117.12$

$(14.10)$

(9.79)

BMI gain between 8 and 18

years (SD)

$>0.67$

$\leq 0.67$

Height

$\leq$ Median

$>$ Median

Waist circumference \#\#

Increased

Normal

BMI

Overweight/obesity

Adequated/thinness

FMI

Excess body fat

Normal body fat

Physical exercise

Sedentary

$138(66.6) \quad 117.31$

(12.92) 0.98

69 (44.4) $\quad 117.26$

(12.86)

72.24

(8.68) $\quad 0.262$

Active

$20(14.2) \quad 119.60$

$\begin{array}{lll}(12.21) & 0.640 \quad 75.90\end{array}$

$\begin{array}{ll}(13.61) & 72.23\end{array}$

$\begin{array}{ll}(8.30) & 0.079\end{array}$

$121(85.8) \quad 118.08$

$\begin{array}{lll}(12.58) & 0.029 & 70.54\end{array}$

(8.65)

$108(51.9) \quad 115.39$

(12.92)

(7.94) $\quad 0.039$

$100(48.1) \quad 119.26$

72.99

(9.04)

$39(19.0) \quad 119.05$

$\begin{array}{lll}(12.71) & 0.367 & 72.44\end{array}$

$\begin{array}{ll}(9.26) & 0.629\end{array}$

$166(81.0) \quad 116.98$

(13.57)

71.70

(8.34)

$42(20.2) \quad 121.81$

$\begin{array}{lll}(11.14) & 0.010 \quad 74.45\end{array}$

(7.80) $\quad 0.020$

$166(79.8) \quad 116.09$

(13.04)

71.01

(8.61)

95 (48.5) $\quad 117.44$

$\begin{array}{lll}(11.40) & 0.750 \quad 73.74\end{array}$

(7.64) $\quad 0.017$

$101(51.5) \quad 118.02$

(13.81)

70.91

(8.72)

$\begin{array}{lllll}71(34.1) & 114.35 & (10.50) & 0.018 \quad 72.38\end{array}$

(7.50) $\quad 0.416$

$137(65.9) \quad 118.76 \quad(13.74) \quad 71.36 \quad(9.05)$ 
634 TABLE 2. Frequency of systemic arterial elevated blood pressure in adolescents according 635 to variables at birth. in childhood and adolescence

\begin{tabular}{|c|c|c|c|c|c|}
\hline \multirow[t]{3}{*}{ Variables } & \multicolumn{5}{|c|}{ Systemic Blood Pressure } \\
\hline & \multicolumn{2}{|c|}{$\begin{array}{l}\text { Elevated blood } \\
\text { pressure }\end{array}$} & \multicolumn{2}{|c|}{ Normal } & \multirow[b]{2}{*}{$\mathrm{P}$} \\
\hline & $\mathrm{n}=78$ & $\%$ & $\mathrm{n}=130$ & $\%$ & \\
\hline \multicolumn{6}{|l|}{ At birth } \\
\hline \multicolumn{6}{|l|}{ Sex } \\
\hline Male & 48 & 57.1 & 36 & 42.9 & $<0.0001$ \\
\hline Female & 30 & 24.2 & 94 & 75.8 & \\
\hline \multicolumn{6}{|l|}{ Birth weight } \\
\hline Low weight & 23 & 32.4 & 48 & 67.6 & 0.294 \\
\hline Appropriate weight & 55 & 40.1 & 82 & 59.9 & \\
\hline \multicolumn{6}{|l|}{ Maternal height (cm) } \\
\hline$\geq 150$ & 68 & 40.5 & 100 & 59.5 & 0.073 \\
\hline$<150$ & 10 & 25.0 & 30 & 75.0 & \\
\hline \multicolumn{6}{|l|}{ Family income (MW) } \\
\hline$<1$ & 41 & 33.3 & 82 & 66.7 & 0.147 \\
\hline$\geq 1$ & 37 & 43.5 & 48 & 56.5 & \\
\hline \multicolumn{6}{|l|}{ At six month } \\
\hline \multicolumn{6}{|l|}{$\overline{\text { Postnatal weight gain (SD) }}$} \\
\hline$>0.67$ & 32 & 51.6 & 30 & 48.4 & 0.002 \\
\hline$\leq 0.67$ & 25 & 26.6 & 69 & 73.4 & \\
\hline \multicolumn{6}{|l|}{ At 8 years } \\
\hline \multicolumn{6}{|l|}{ BMI } \\
\hline Overweight/obesity & 20 & 62.5 & 12 & 37.5 & 0.004 \\
\hline Adequated/thinness & 40 & 33.9 & 78 & 66.1 & \\
\hline \multicolumn{6}{|l|}{ Waist circumference } \\
\hline Increased & 13 & 76.5 & 4 & 23.5 & 0.003 \\
\hline Normal & 47 & 35.3 & 86 & 64.7 & \\
\hline \multicolumn{6}{|l|}{$\begin{array}{l}\text { BMI gain between } 6 \text { month and } 8 \text { years } \\
\text { (SD) }\end{array}$} \\
\hline$>0.67$ & 10 & 52.6 & 9 & 47.4 & 0.207 \\
\hline$\leq 0.67$ & 35 & 36.5 & 61 & 63.5 & \\
\hline \multicolumn{6}{|l|}{ At 18 years } \\
\hline$\overline{\text { Per capita family income (MW) }}$ & 55 & 39.9 & 83 & 60.1 & 0.447 \\
\hline $\begin{array}{l}<0.5 \\
\geq 0.5\end{array}$ & 23 & 33.3 & 46 & 66.7 & \\
\hline BMI gain between 8 and 18 years (SD) & 8 & 40.0 & 12 & 60.4 & 1.000 \\
\hline $\begin{array}{l}>0.67 \\
\leq 0.67\end{array}$ & 51 & 42.1 & 70 & 57.9 & \\
\hline Height & 33 & 30.6 & 75 & 69.4 & 0.044 \\
\hline$\leq$ Median & 45 & 45.0 & 55 & 55.0 & \\
\hline > Median & & & & & \\
\hline Waist circumference & 16 & 41.0 & 23 & 59.0 & 0.716 \\
\hline Increased & 62 & 37.3 & 104 & 62.7 & \\
\hline \multicolumn{6}{|l|}{ BMI } \\
\hline Overweight/obesity & 19 & 45.2 & 23 & 54.8 & 0.286 \\
\hline Adequated/thinness & 59 & 35.5 & 107 & 64.5 & \\
\hline \multicolumn{6}{|l|}{ FMI } \\
\hline Excess body fat & 36 & 37.9 & 59 & 62.1 & 0.770 \\
\hline Normal body fat & 41 & 40.6 & 60 & 59.4 & \\
\hline \multicolumn{6}{|l|}{ Physical exercise } \\
\hline Sedentary & 21 & 29.6 & 50 & 70.4 & 0.098 \\
\hline Active & 57 & 41.6 & 80 & 58.4 & \\
\hline
\end{tabular}


TABLE 3. Logistic regression of factors associated with elevated blood pressure in adolescents aged 18 years

\begin{tabular}{|c|c|c|c|c|c|c|}
\hline \multirow[t]{2}{*}{ Variables } & \multicolumn{3}{|c|}{ Unadjusted OR } & \multicolumn{3}{|c|}{ Adjusted OR } \\
\hline & OR & $(95 \% \mathrm{CI})$ & $\mathbf{P}$ & OR & $(95 \% \mathrm{CI})$ & $\mathbf{P}$ \\
\hline \multicolumn{7}{|l|}{ Block 1} \\
\hline Postnatal weight gain (>0.67SD) & 2.94 & $(1.50-5.79)$ & 0.002 & 2.74 & $(1.22-6.14)$ & 0.014 \\
\hline $\begin{array}{l}\text { Waist circumference at } 8 \text { years } \\
\text { (increased) }\end{array}$ & 5.95 & $(1.84-19.27)$ & 0.003 & 3.23 & $(0.87-11.85)$ & 0.078 \\
\hline \multicolumn{7}{|l|}{ Block 2} \\
\hline Maternal height $(\geq 150 \mathrm{~cm})$ & 2.04 & $(0.94-4.45)$ & 0.073 & 1.81 & $(0.55-5.99)$ & 0.329 \\
\hline Adolescent height (>median) & 1.86 & $(1.05-3.28)$ & 0.032 & 1.12 & $(0.47-2.66)$ & 0.807 \\
\hline \multicolumn{7}{|l|}{ Block 3} \\
\hline Physical activity level (active) & 1.70 & $(0.92-3.13)$ & 0.091 & 2.70 & $(1.08-6.74)$ & 0.034 \\
\hline \multicolumn{7}{|l|}{ Block 4} \\
\hline Sex (male) & 4.18 & $(2.30-7.59)$ & $<0.001$ & 4.15 & $(1.66-10.38)$ & 0.002 \\
\hline
\end{tabular}

All variables remained in the logistic regression analysis 
677 APPENDIX 1. Socioeconomic and maternal characteristics at birth of adolescents traced 678 and those lost to follow-up according to birth weight

\begin{tabular}{|c|c|c|c|c|c|c|}
\hline & \multicolumn{3}{|c|}{ Low birth weight $(\mathrm{n}=206)$} & \multicolumn{3}{|c|}{ Appropriate birth weight $(n=343)$} \\
\hline & $\begin{array}{c}\text { Lost } \\
\mathrm{n}=132\end{array}$ & $\begin{array}{l}\text { Traced } \\
n=74\end{array}$ & & $\begin{array}{c}\text { Lost } \\
\mathbf{n}=\mathbf{2 0 0}\end{array}$ & $\begin{array}{l}\text { Traced } \\
n=143\end{array}$ & \\
\hline & $\mathbf{n}(\%)$ & n (\%) & $\mathbf{p}$ & $\mathbf{n}(\%)$ & $\mathrm{n}(\%)$ & $\mathbf{P}$ \\
\hline \multicolumn{7}{|l|}{ Sex } \\
\hline Male & $61(66.3)$ & $31(33.7)$ & 0.651 & $89(61.8)$ & $55(38.2)$ & 0.314 \\
\hline Female & $71(62.3)$ & $43(37.7)$ & & $111(55.8)$ & $88(44.2)$ & \\
\hline \multicolumn{7}{|l|}{$\begin{array}{l}\text { Smoking } \\
\text { during } \\
\text { pregnancy }\end{array}$} \\
\hline Yes & $43(74.1)$ & $15(25.9)$ & 0.085 & $39(58.2)$ & $28(41.8)$ & 0.905 \\
\hline No & $89(60.1)$ & 59 (39.9) & & $161(58.3)$ & $115(41.7)$ & \\
\hline \multicolumn{7}{|l|}{$\begin{array}{l}\text { Maternal } \\
\text { schooling } \\
\text { (years) }\end{array}$} \\
\hline Never studied & $23(63.9)$ & $13(36.1)$ & 0.716 & $36(64.3)$ & $20(35.7)$ & 0.074 \\
\hline 1 to 4 & $96(65.3)$ & $51(34.7)$ & & $137(60.1)$ & $91(39.9)$ & \\
\hline$\geq 5$ & $13(56.5)$ & $10(43.5)$ & & $27(45.8)$ & $32(54.2)$ & \\
\hline \multicolumn{7}{|c|}{$\begin{array}{l}\text { Family income } \\
\text { (MW) }\end{array}$} \\
\hline$\leq 1$ & $93(67.9)$ & $44(32.1)$ & 0.219 & $112(57.1)$ & $84(42.9)$ & 0.270 \\
\hline $1.01-2.0$ & $30(54.5)$ & $25(45.5)$ & & $63(64.3)$ & $35(35.7)$ & \\
\hline$>2.0$ & $9(64.3)$ & $5(35.7)$ & & $25(51.0)$ & $24(49.0)$ & \\
\hline \multicolumn{7}{|l|}{$\begin{array}{l}\text { Family size } \\
\text { (people) }\end{array}$} \\
\hline$\leq 4$ & $77(68.1)$ & $36(31.9)$ & 0.232 & $97(51.9)$ & $90(48.1)$ & 0.011 \\
\hline$>4$ & $55(59.1)$ & $38(40.9)$ & & $103(66.0)$ & $53(34.0)$ & \\
\hline
\end{tabular}

679 Yates corrected chi-square. Significance level $\mathrm{p} \leq 0.05 . \mathrm{MW}-$ minimum wage. 